\title{
SUFFICIENT CONDITIONS FOR THE EXPONENTIAL STABILITY OF NONLINEAR FRACTIONALLY PERTURBED ODE $s$ WITH MULTIPLE TIME DELAYS
}

\author{
Milan MedveĎ And Eva BREstovansKá
}

Abstract. In this paper we prove some results on the exponential stability of the trivial solution of a system of fractional differential equations with multiple delays and tempered RiemannLouville fractional integrals on its right-hand side.

Mathematics subject classification (2010): 26D15, 26A51, 32F99, 41A17.

Keywords and phrases: Fractional tempered derivative, fractional tempered integral, fractional perturbation of ODE, multi-delay, exponential stability.

\section{REFERENCES}

[1] B. BAEMER, M. M. MEerschaert, Tempered stable Lévy motion and transient super-diffusion, Journal of Computational and Applied Math. 233 (2010), 2438-2448.

[2] G. E. Bredon, Topology and Geometry, Springer-Verlag, New York, 1993.

[3] E. BRESTOVAnsKÁ, M. MEDVEĎ, Exponential stability of solutions of nonlinear fractionally perturbed ordinary differential equations, EJDE 2017, 280 (2017), 1-17.

[4] E. BREstovAnsKÁ, M. MEDVEĎ, Exponential stability of solutions of a second order systems of integrodifferential equations with the Caputo-Fabrizio fractional derivatives, Progr. Fract. Differ. Appl. 2, 3 (2016), 178-192.

[5] M. Chen, W. Deng, Discretized fractional substantial calculus, Math. Model. Numer. 49, 2 (2015), 373-394.

[6] W. A. Coppel, Stability and Asymptotic behavior of Differential Equations, D.C.Heath, Boston, Mass, USA 1965.

[7] K. M. FurAti, N. E. TATAR, Power type estimate for a nonlinear fractional differential equations, Nonlinear Analysis 62 (2005), 1025-1036.

[8] M. KirAne, M. Medveň, N. E. TATAR, Semilinear Volterra integrodifferential problems with fractional derivatives in the nonlinearities, Abstract and Applied Analysis, 2011 (2011), Article ID 510314.

[9] C. Li, W. DENG, L. ZHAO, Well-posedness and numerical algorithm for the tempered fractional ordinary differential equations, arXiv:1501.00376vl [math.CA] (2015).

[10] C. P. LI, F. R. ZHANG, A survey on the stabiliy of fractional differential equations, Eur. Phys. J., Special Topics 193 (2011), 27-47.

[11] Y. Lountssasi, E. H. E. Mazoudi, N. Elalami, A new generalization of lemma GronwallBellman, Applied Math. Sciences 6, 13 (2011),621-628.

[12] R. MEDINA, New conditions for the exponential stability of nonlinear differential equations, Abstract and Applied Math. 2017, 1 (2017), 261-281.

[13] R. MEDINA, Exponential stability criteria for systems with multiple time delays, IMA Journal of Mathematical Control and Information 2 (2017), 1-16.

[14] M. MEdVEĎ, E. BRESTOVANSKÁ, New conditions for the exponential stability of fractionally perturbed ODEs, EJQTDE, 84 (2018), 1-14.

[15] M. MEDVEĎ, E. BRESTOVAnSKÁ, New conditions for the exponential stability of fractionally perturbed ODEs, Electron. J. Qual. Theory Differ. Equ. 84 (2018) 1-14. Corrigendum: Electron. J. Qual. Theory Differ. Equ. 102 (2018) 1-2. 
[16] M. MEdVEĎ, M. PospíšIL, L. ŠKRIPKOVÁ, Stability and nonexistence of blowing-up solutions of nonlinear delay systems with linear parts defined by permutable matrices, Nonlinear Analysis $\mathbf{7 4}$ (2011), 3903-3911.

[17] M. MedveĎ, M. PospíšIL, L. ŠKRIPKOVÁ, On exponential stability of nonlinear fractional multidelay integro-differential equations defined by defined by pairwise permutable matrices, Applied Mathematics and Computations, 227 (2014), 456-468.

[18] M. Medveऽ̌, M. PospíšIL, Sufficient conditions for the asymptotic stability of nonlinear multidelay differential equations with linear parts defined by pairwise permutable matrices, Nonlinear Analysis, 75 (2012), 3348-3363.

[19] M. MedveĎ, M. PospíšIL, On the existence and exponential stability for differential equations with multiple constant delays and nonlinearity depending on fractional sustantial intrgals, EJQTDE, 43 (2019), 1-17.

[20] M. M. Meerschaert, F. SABZIKAR, Stochastic integration for tempered fractional Brownian motion, Stochastic Processes and their Applications, 124 (2014), 2363-2387.

[21] A. Mesbahi, M. Haeri, M. NAZARI, E. Butcher, Fractional delayed damped Mathieu equation, International J. Control, 88, 3 (2015), 622-630.

[22] M. Morgado, M. Rebelo, Well-posedness and numerical approximation of tempered terminal value problem, Fractional Calculus and Applied Analysis, 205 (2017), 1239-1261.

[23] M. NABER, Linear fractionally damped oscillator, International Journal of Differential Equations 2010 (2010), Art ID 197020, 12 pages.

[24] J. I. Nwamba, Delayed Mathieu equation with fractional order damping: An approximate analytic solution, International J. Mech. Appl., 3, 4 (2013), 70-75.

[25] M. Seredynska, A. HANyga, Nonlinear differential equations with fractional damping with applications to the 1dof and 2dof pendulum, Acta Mechanica, 176 (2005), 169-183.

[26] I. SCHÄFER, S. KEMPELE, Impulse responses of fractionallz damped systems, Nonlinear Dynamics, 38 (2004), 61-68.

[27] Z. J. Jiao, Y. Q. Chen, I. Podlubny, Distributed-Ordered Dynamical Systems: Stability, Simulations, Applications and Perspectives, Springer, London, Heidelberg, New York, Dortrecht 2012.

[28] S. S. RAY, S. ShaO, Generalized Fractional order Differential Equations Arising in Physical Models, CRC Press, Taylor and Francis Group, London, New York 2019.

[29] S. STANĚK, Two-point boundary value problems for the generalized Bargley-Torvik fractional differential equations, Nonlinear Dyn., 71 (2013), 574-592.

[30] P. J. TORVIK, R. L. BAGLEY, On the appearance of the fractional derivatives in the behavior of real materials, Trans. ASME J. Appl. Mech. 51 (1984), 294-298.

[31] Y. WANG, F. GAO, P. KLOEDEN, Impulsive fractional functional differential equations with a weakly continuous nonlinearity, EJDE, 2017285 (2017), 1-18. 